\title{
DSTATCOM with Improved LMS based IRP theory
}

\author{
D. Suresh ${ }^{1}, G$. Sravanthi ${ }^{2}$ and R.Chander ${ }^{3}$ \\ ${ }^{12}$ Department of Electrical and Electronics Engineering, Vignan institute of Technology and Science, Deshmukhi \\ ${ }^{3}$ Department of Electrical \&Electronics Engineering, Osmania university college of Engineering, Hyderabad
}

\begin{abstract}
In this paper, grid connected DSTATCOM with three phase three wire has been proposed for harmonics elimination, reactive power compensation and active power injection into the grid. An improved instantaneous reactive power theory based on the least mean square is computed. The least mean square (LMS) algorithm is combined with instantaneous reactive power theory (IRPT) to improve its dynamics performance and eliminates the use of low pass filter requirement for computation of reference current. The harmonics component of the active power is estimated from LMS algorithm generated load harmonics currents. The performance characteristic of DSTATCOM is estimated with control scheme using computer simulation. The technique is based on the instantaneous transformation of instantaneous signals and taking advantage of the subsequent calculation of power from supply side to the loads. The neural network based method to estimate the harmonic online, DSTATCOM can compensate the harmonics. The computer simulation is carried out with MATLAB Simulink power system block sets.
\end{abstract}

\section{Introduction}

In recent time many researchers working on renewable energy source based power quality improvement in the electrical distribution system. There are different types of small power sources such as photovoltaic cell, fuel cell and wind energy [3-9].

The power electronics converter almost used in every consumer electronics and home appliances. The power electronics converters cause harmonics and flow of reactive current. Due to harmonics, AC supply tends to non-sinusoidal at point of common coupling. Also, current and voltage harmonics propagate into utility, which is not useful for developing active power. The generated harmonics causes overheating of conductor, interference with consumer, malfunction of sophisticated instrument and creates serious problems of electromagnetic interference and electromagnetic compatibility [1]. In literature, the performance investigation of active power filters based on different topologies and control schemes are widely studied. Mostly, the shunt active power filter is used for compensation of harmonics and reactive power demand of the load. The shunt active power filters also known as dynamic static compensator (DSTATCOM). The
DSTATCOM is the family of custom power devices, which is used to mitigate the abnormalities due to the current harmonics and it is connected in parallel with load. Unified power quality controller (UPQC), dynamic voltage restorer (DVR), dynamic static compensator etc. are the family of custom power devices. The load contributes the multiple problems such as current harmonics, reactive power burden, voltage harmonics and these problems can be compensated with custom power devices. In addition, DSTATCOM can also be used for integration of the renewable energy sources with grid [2]-[5].

In literature, many numbers of controllers are devised for control of voltage and current of DSTATCOM inverter [3]. The DSTATCOM is connected in shunt with load to compensate the harmonics and reactive power demand of the nonlinear load. This task is accomplished by inject compensating current into the utility system via buffer inductors. In fact, several control methods have been reported in the literature, among them conventional controllers and artificial intelligent controllers are well established. Some of them are model reference adaptive controller, sliding mode control [4], fuzzy control [6,7], adaptive neural network control [8] and neuro-fuzzy control [9]. 
However, these controllers can improve the dynamic performance as well as mitigate the harmonics and reactive power caused by the nonlinear load. Most of the controllers are used for regulating dc voltage of DSTATCOM and the training data is obtained from the conventional proportional plus integral controllers.

In literature many control schemes were proposed to compute the reference current of the DSTATCOM to track desired source current. Among them, the most widely used schemes are IRPT and synchronous reference frame theories. Conversely, these control strategies requires more number of transformation to estimate the compensating currents $[6$, $7,10][11]$. Consequently, the numbers of transformation also requires more number of multipliers and increase the level complexity for estimation of reference currents to the DSTATCOM [9].

In this article, control scheme is proposed to the integrate the least mean square with IRPT scheme. This control strategy is used for computations of desired current for tracking the source current of diode clamped multilevel inverter (DCMLI) based DSTATCOM [6]. However, conventional control scheme implantation on the digital platform is less complex and can achieve good results. Moreover, conventional IRPT require low pass filter for estimation of oscillating active power. The oscillating active power along with reactive power is used for estimation of compensating current of DSTATCOM. The low pass filter which is used for estimation of oscillating power is not adaptive and parameter adjustment of low pass filter is tedious task. In the proposed control scheme, the low pass filter is replaced with LMS algorithm to estimate the harmonics active power and subsequent calculation of the reference current for the DSTATCOM.

\section{Topology of three level DSTATCOM}

The DCMLI based DSTATCOM is shown in Fig.1. The DSTATCOM circuit consists of interfacing inductor, dc link capacitor and twelve insulated gate bipolar transistor. The DSTATCOM is connected at load side to compensate the abnormalities caused by the load such as harmonics and reactive power burden. The photo voltaic modules are integrated on the DC side of the DSTATCOM.

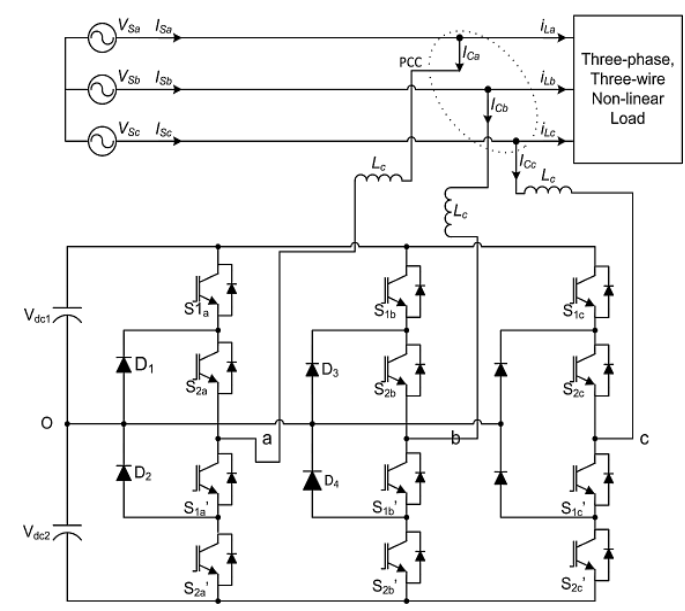

Fig. 1. DCMLI based DSTATCOM.

\section{Photo voltaic cell}

The approximate constant current model of the Photo voltaic cell is shown in the Fig. 2 .

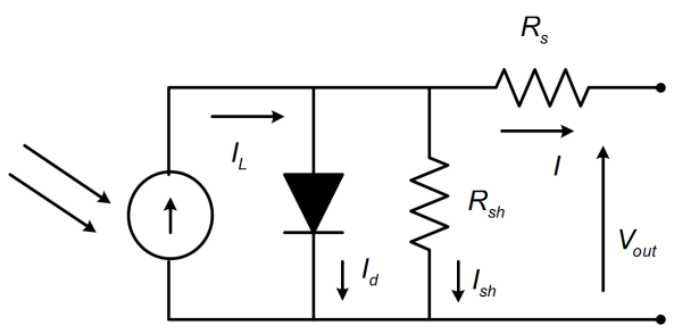

Fig. 2. Photo voltaic cell model.

The equation, which is used to define I-V characteristics photo voltaic cell is as follows

$$
I=I_{L}-I_{d}-I_{s h}=I_{L}-I_{D}\left[e \frac{q V_{o c}}{C k T}-1\right]-\frac{V_{o u t}+R_{S} I}{R_{s h}}
$$

Where $I_{D}$ is the saturation current, $q$ is the electron charge $\left(1.6 \times 10^{-19} C\right), C$ is the diode emission factor, $k$ is the Boltzmann constant $\left(1.38 \times 10^{-23} \mathrm{~J} / \mathrm{K}\right)$ and $T$ is the temperature.

The maximum power generated from the photo voltaic cell is at the knee point of the I-V curve as it can be seen from Fig.3. 


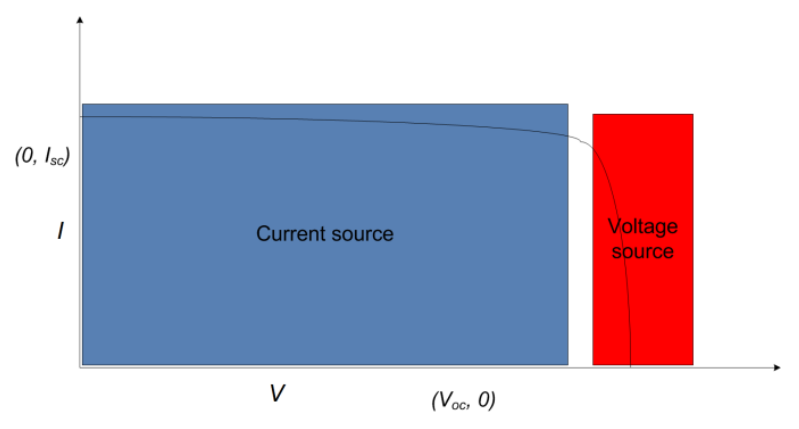

Fig. 3. V-I characteristics of photo voltaic cell.

The maximum power is the product of maximum value of voltage and current. The DSTATCOM is set to operate at optimal voltage to achieve maximum power by maximum power point tracking algorithm.

In this paper, the incremental conductance and integral regulator technique used for tracking the maximum power from the photo voltaic modules [6]. This MPPT method is based on the fact that the power slope of the PV is null at MPP point (Where $d p / d v=0$ ), positive in the left, and negative in the right. In the following equations, $d v$ and $d i$ are obtained by one-sample delayed values $\mathrm{V}$.

$\frac{d p}{d v}=\frac{d(v i)}{d v}=i+v \frac{d i}{d v}=0$

$\frac{d v}{d i}=-\frac{i}{v}$

$\left\{\begin{array}{l}\frac{d v}{d i}>\frac{i}{v}: \text { left } \\ \frac{d v}{d i}<\frac{i}{v}: \text { right }\end{array}\right.$

\section{CONTROL SCHEME}

The instantaneous reactive power theory is based on the transformation of quantities and subsequent calculation of real and reactive power ( $p-q$ or IRP theory). It is the based on time domain scheme. The application of IRPT can be extended to the three phase or four phase with small modification in computation of reference theory.

Let the system terminal voltages be given as,

$$
\begin{aligned}
& v_{S a}=v_{m} \cos (\omega t) \\
& v_{S b}=v_{m} \cos \left(\omega t-\frac{2 \pi}{3}\right) \\
& v_{S c}=v_{m} \cos \left(\omega t-\frac{4 \pi}{3}\right)
\end{aligned}
$$

The $p$ - $q$ theory starts with the transformation of threephase voltage and currents into $\alpha \beta 0$ stationary reference frame. The Clarke transformation maps the three-phase instantaneous voltages in the $a b c$-phases, $v_{S a}, v_{S b}$, and $v_{S c}$, into the instantaneous voltages on the $\alpha \beta 0$-axes $v_{\alpha}$, $v_{\beta}$, and $v_{0}$ as,

$\left[\begin{array}{l}v_{0} \\ v_{\alpha} \\ v_{\beta}\end{array}\right]=\sqrt{\frac{2}{3}}\left[\begin{array}{ccc}\frac{1}{\sqrt{2}} & \frac{1}{\sqrt{2}} & \frac{1}{\sqrt{2}} \\ 1 & -\frac{1}{2} & -\frac{1}{2} \\ 0 & \frac{\sqrt{3}}{2} & -\frac{\sqrt{3}}{2}\end{array}\right]\left[\begin{array}{l}v_{S a} \\ v_{S b} \\ v_{S c}\end{array}\right]$

Similarly, three-phase instantaneous compensating currents in the $a b c$-phases, $i_{c a}, i_{c b}$, and $i_{c c}$, are transformed into the instantaneous currents on the $\alpha \beta 0$ axes $i_{\alpha}, i_{\beta}$, and $i_{0}$ as,

$\left[\begin{array}{l}i_{0} \\ i_{\alpha} \\ i_{\beta}\end{array}\right]=\sqrt{\frac{2}{3}}\left[\begin{array}{ccc}\frac{1}{\sqrt{2}} & \frac{1}{\sqrt{2}} & \frac{1}{\sqrt{2}} \\ 1 & -\frac{1}{2} & -\frac{1}{2} \\ 0 & \frac{\sqrt{3}}{2} & -\frac{\sqrt{3}}{2}\end{array}\right]\left[\begin{array}{l}i_{c a} \\ i_{c b} \\ i_{c c}\end{array}\right]$

As no zero-sequence component exists in the $3 \mathrm{P} 3 \mathrm{~W}$ systems, $v_{0}$ and $i_{0}$ can be eliminated in equations and, respectively.Elimination of $v_{0}$ from equation leads to,

$\left[\begin{array}{c}v_{\alpha} \\ v_{\beta}\end{array}\right]=\sqrt{\frac{2}{3}}\left[\begin{array}{rrr}1 & -\frac{1}{2} & -\frac{1}{2} \\ 0 & \frac{\sqrt{3}}{2} & -\frac{\sqrt{3}}{2}\end{array}\right]\left[\begin{array}{l}v_{S a} \\ v_{S b} \\ v_{S c}\end{array}\right]$

Similarly, elimination of $i_{0}$ from equation (4) leads to,

$\left[\begin{array}{l}i_{\alpha} \\ i_{\beta}\end{array}\right]=\sqrt{\frac{2}{3}}\left[\begin{array}{rrr}1 & -\frac{1}{2} & -\frac{1}{2} \\ 0 & \frac{\sqrt{3}}{2} & -\frac{\sqrt{3}}{2}\end{array}\right]\left[\begin{array}{l}i_{c a} \\ i_{c b} \\ i_{c c}\end{array}\right]$

The instantaneous value of active and reactive expressed as follows

$$
\begin{aligned}
& p=v_{\alpha} i_{\alpha}+v_{\beta} i_{\beta} \\
& q=-v_{\beta} i_{\alpha}+v_{\alpha} i_{\beta} \\
& {\left[\begin{array}{l}
p \\
q
\end{array}\right]=\left[\begin{array}{cc}
v_{\alpha} & v_{\beta} \\
-v_{\beta} & v_{\alpha}
\end{array}\right]\left[\begin{array}{l}
i_{\alpha} \\
i_{\beta}
\end{array}\right]}
\end{aligned}
$$

The instantaneous value of active and reactive powers $p$ and $q$ can be computed from IRPT scheme. Further decomposed as DC and AC power and as follows

$$
\left[\begin{array}{l}
p \\
q
\end{array}\right]=\left[\begin{array}{l}
\bar{p}+\tilde{p} \\
\bar{q}+\tilde{q}
\end{array}\right]
$$


The DSTATCOM is used to compensate the alternating component of the active power. The oscillatory component of active power obtained with low pass filter $\tilde{p}=\bar{p}-p$. In addition to this, DSTATCOM has to compensate reactive power $q=\bar{q}+\tilde{q}$. This can be calculated directly from the transformed quantities. The compensating currents of the DSTATCOM are calculated in $\alpha \beta 0$-reference frame as

$$
\left[\begin{array}{l}
i_{C \alpha}^{*} \\
i_{C \beta}^{*}
\end{array}\right]=\frac{1}{v_{\alpha}^{2}+v_{\beta}^{2}}\left[\begin{array}{cc}
v_{\alpha} & v_{\beta} \\
v_{\beta} & -v_{\alpha}
\end{array}\right]\left[\begin{array}{c}
-\tilde{p} \\
-(\bar{q}+\tilde{q})
\end{array}\right]
$$

The significance of the negative sign is used to specify the action of DSTATCOM. This sign indicate the DSTATCOM should draw the compensating current, which is in phase opposition to the load current. Let $P_{\text {loss }}$ be the power required meet to temporary load demand and to overcome the capacitive power leakage losses. The compensating power $P_{\text {loss }}$ can be obtain by comparing the reference voltage with measured value and processed in proportional integral controller. As a result, equation becomes,

$$
\left[\begin{array}{l}
i_{C \alpha}^{*} \\
i_{C \beta}^{*}
\end{array}\right]=\frac{1}{v_{\alpha}^{2}+v_{\beta}^{2}}\left[\begin{array}{cc}
v_{\alpha} & v_{\beta} \\
v_{\beta} & -v_{\alpha}
\end{array}\right]\left[\begin{array}{c}
-p_{C}+p_{\text {Loss }} \\
-q_{C}
\end{array}\right]
$$

These compensating currents in $\alpha \beta 0$ frame can be used to compute the $a b c$ quantities using inverse Clarke's transformation as,

$$
\left[\begin{array}{l}
i_{C a}^{*} \\
i_{C b}^{*} \\
i_{C c}^{*}
\end{array}\right]=\sqrt{\frac{2}{3}}\left[\begin{array}{cc}
1 & 0 \\
-\frac{1}{2} & \frac{\sqrt{3}}{2} \\
-\frac{1}{2} & -\frac{\sqrt{3}}{2}
\end{array}\right]\left[\begin{array}{l}
i_{C \alpha}^{*} \\
i_{C \beta}^{*}
\end{array}\right]
$$

The control scheme based on IRPT is shown in Fig.2.

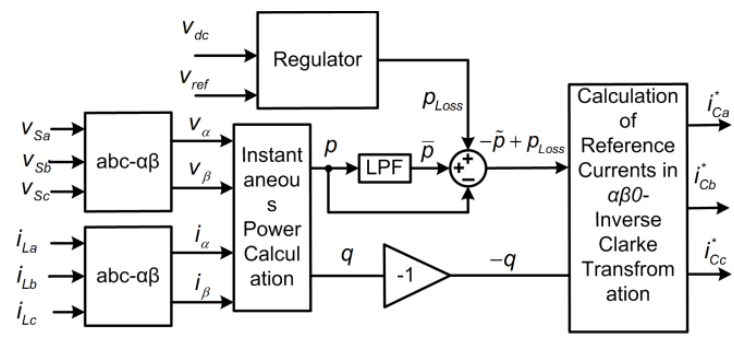

Fig. 4. Instantaneous reactive power theory.

\section{Modified PQ theory based on LMS algorithm}

The load current can be expressed as

$$
i_{L}=I_{m 1} \cos (\omega t-\phi)+\sum_{n=2}^{\infty} I_{m n} \cos \left(n \omega t-\phi_{n}\right)
$$

The source voltage harmonics and expressed as

$$
v_{s}=V_{m} \cos (\omega t)
$$

This can be further written as

$$
v_{s}=V_{m} \cos (-\omega t)
$$

The instantaneous active power can be calculated from frequency analysis as

$$
\begin{aligned}
& p(t)=V_{m} I_{m 1} \cos \left(\phi_{1}\right) \\
& +\sum_{n=2}^{\infty} V_{m} I_{m n} \cos \left(\omega t(n-1)-\phi_{n}\right)
\end{aligned}
$$

The value of instantaneous active power can be expressed as

$$
\begin{aligned}
& p(t)=p_{m 1} \cos \left(\phi_{1}\right) \\
& +\sum_{n=2}^{\infty} p_{m n} \cos \left(\omega t(n-1)-\phi_{n}\right) \\
& p(t)=\bar{p}(t)+\tilde{p}
\end{aligned}
$$

The oscillating component of the active power can be expressed as

$$
\tilde{p}=\bar{p}(t)-p(t)
$$

Where

$$
\begin{aligned}
& W=\left[\cos \left(\phi_{1}\right) \sin \left(\phi_{2}\right) \cos \left(\phi_{2}\right) \ldots \sin \left(\phi_{n}\right) \cos \left(\phi_{n}\right)\right] \\
& X^{T}=[1 \cos (\omega t) \sin (\omega t) \ldots \cos (N \omega t) \sin (N \omega t)]^{T}
\end{aligned}
$$

The LMS algorithm used for estimation of the harmonics component of active power is expressed as

$W_{(n+1)}=W_{n}+\eta(d-Y) X$ 


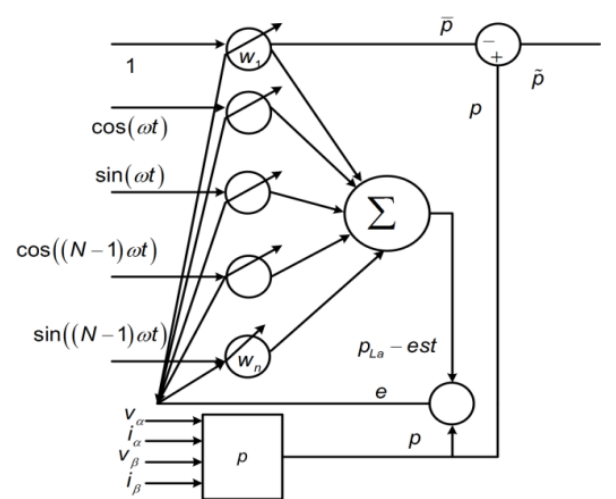

Fig. 5. Estimation harmonics component of active power.

Where, $\eta$ is the constant also known as learning rate. The convergence value of learning rate is from 0.1 to 1.0. The control diagram is shown in Fig.2. The LMS algorithm eliminates the requirement of low pass filter in improved IRPT. The LMS based estimation of oscillatory component of the current is depicted in Fig.3. And control scheme based on LMS integrated with IRPT is shown in Fig.4.

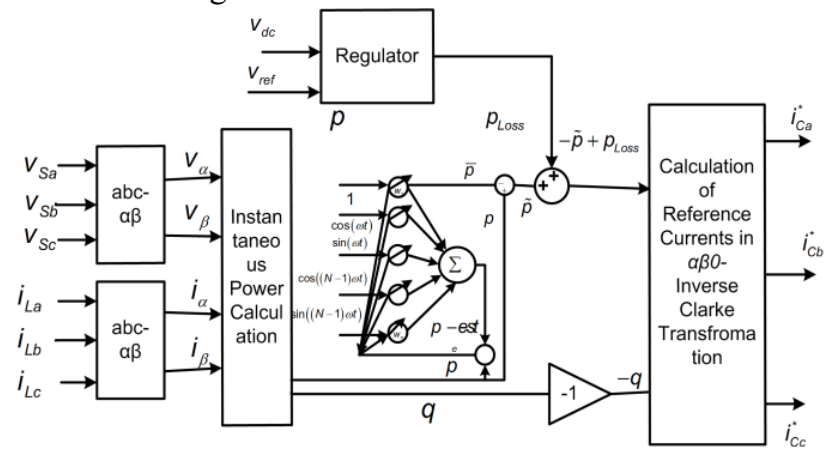

Fig. 6. LMS based IRPT control scheme.

\section{Simulation results and discussion}

The simulation model of the DSTATCOM and its control scheme is implemented with MATLAB/Simulink power system block sets. The nonlinear load is implemented with diode bridge rectifiers. The diode bridge rectifier generates the waveforms which is seems to be in stepped waveform in shape. The stepped waveform contains triplen harmonics current. The instantaneous value of the load voltage and currents are used to estimate the compensating currents with IRPT scheme.

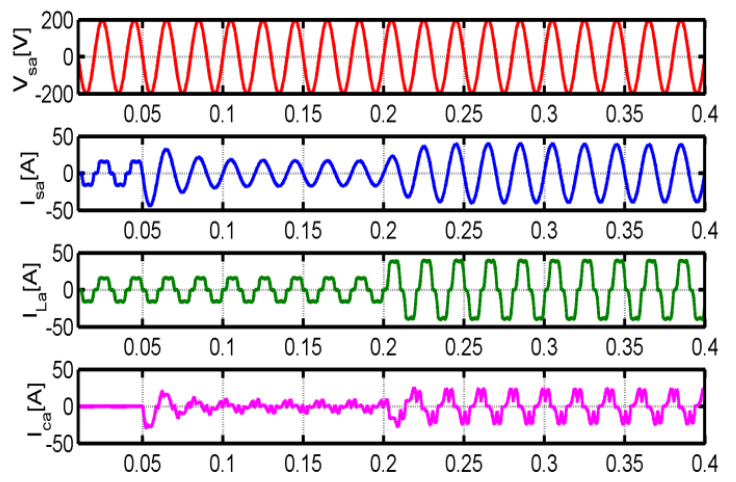

(a)

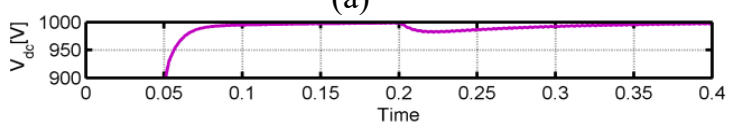

(b)

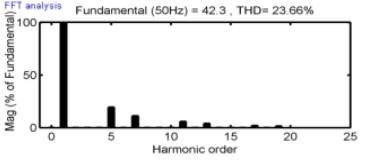

(c)

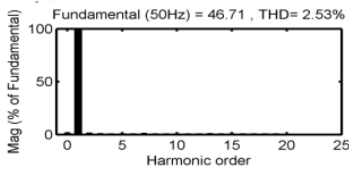

(d)
Fig. 7. Performance of the DSTATCOM with LMS based IRPT.

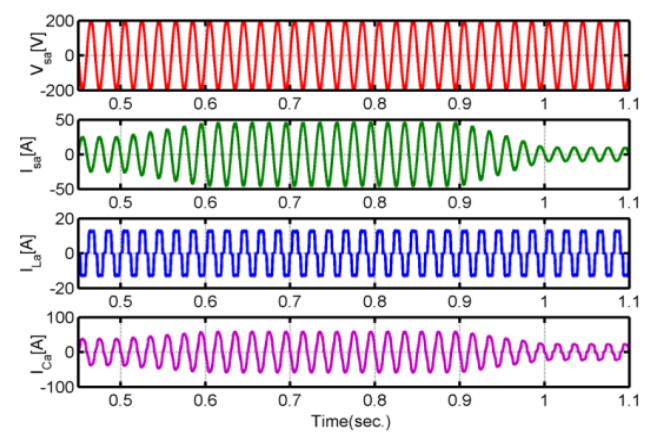

(a)
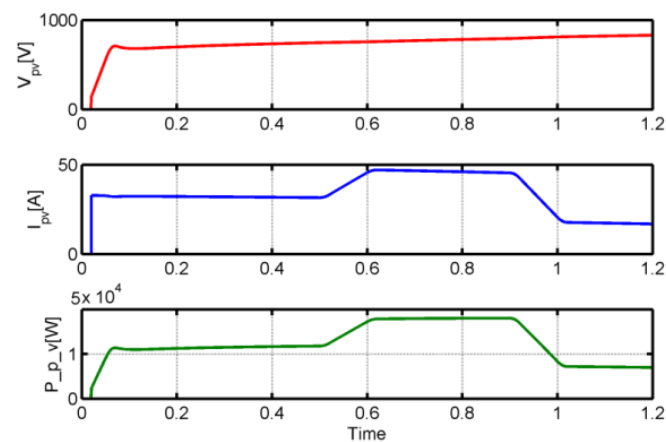

(b)

Fig. 8. DSTATCOM waveform with photo voltaic module

The diode bridge rectifier used as nonlinear load. The rectifier circuit consists of commutation inductance on input side and resistive-inductive elements on load side as non-linear load. The characteristics DSTATCOM while feeding the non-linear load is depicted in Fig. 5 (a)-(d). The waveforms of DSTATCOM characteristics are obtained with MATLAB simulations. The waveforms are identified as follows: source-voltage, source-current, load-current, compensating-current, dc link voltage across the capacitors. The control scheme under consideration is the LMS-IRPT for DSTATCOM. After the compensation with DSTATCOM currentwaveform is tends to sinusoidal from stepped waveform. The power factor of source is almost unity.

After compensation with DSTATCOM, Source phase current is tends to sinusoidal. The source power factor is almost unity and source phase current is in phase with source voltage. At the instant DSTATCOM is ON, the source current THD reduced to the value $3.41 \%$ as 
depicted in Fig.5 (d) with LMS-IRPT scheme. But the load current THD remains at value $26.7 \%$. The DC link side voltage of DSTATCOM is controlled at the reference levels with LMS-IRPT based schemes. The transient study shows that the DSTATCOM have settling time such as 0.05 for LMS-IRPT scheme. As the load changes at $\mathrm{t}=0.3 \mathrm{~s}$, from $20.2 \mathrm{~A}$ to $40 \mathrm{~A}$. As load current changes, then the equivalent change in source current and dc link voltage is detected. This leads to the increase in current injected by the DSTATCOM, which are results in decrease of DC link capacitor voltages. This decrease in voltage is used to compensate the load demand. The change in voltage is detected from the Fig 5. (b) Conversely, the increase of current injected by the DSTATCOM is gradually in case of the LMS-IRPT.

The current, voltage and power waveform shown in Fig.6. (a) and Fig.6.(b) respectively. At the instant when DSTATCOM is switched ON, the active power generated in photo voltaic cells is injected into the grid. These are observed from variation in source currents and compensating current of the DSTATCOM. The maximum power also tracked from the using incremental conductance method. and variation in the power also shown in Fig.6(b).

\section{Conclusion}

The LMS based IRPT control scheme is derived for control of DSTATCOM to mitigate the abnormalities caused by nonlinear load. The LMS algorithm eliminates the uses of the low pass filter in the IRPT theory. The LMS algorithm is used for estimation of the oscillatory component of the active power and subsequent computation of reference current. The simulated response shows that the LMS-IRPT exhibits the better compensation characteristics and active power injection from the photo voltaic cells

\section{Acknowledgments}

Thanks to the Science and Engineering board and DST government of India for providing grant under ECR/2016/000813.

\section{Reference}

1. B. Singh, K. Al-Haddad and A. Chandra, "A review of active filters for power quality improvement," in IEEE Tran., on Ind. Electron., vol. 46, no. 5, pp. 960-971, Oct 1999.

2. D. M. Divan, S. Bhattacharya, and B. Banerjee, "Synchronous frame harmonic isolator using active series filter," in Proc. Eur. Power Electron. Conf., , pp. 3030-3035, 1991.

3. A. Chandra, B. Singh, B. N. Singh and K. AlHaddad, "An improved control algorithm of shunt active filter for voltage regulation, harmonic elimination, power-factor correction, and balancing of nonlinear loads," in IEEE Transactions on Power Electronics, vol. 15, no. 3, pp. 495-507, May 2000.
4. B. Singh and J. Solanki, "An Implementation of an Adaptive Control Algorithm for a ThreePhase Shunt Active Filter," in IEEE Transactions on Industrial Electronics, vol. 56, no. 8, pp. 2811-2820, Aug. 2009.

5. H. Li, Z. Wu and F. Liu, "A Novel Variable Step size Adaptive Harmonic Detecting Algorithm Applied to Active Power Filter," 2006 IEEE International Conference on Industrial Technology, Mumbai, 2006, pp. 574-578.

6. B. Singh, Sunil Kumar Dube, Sabha Raj Arya, A. Chandra and K. Al-Haddad, "A comparative study of adaptive control algorithms in Distribution Static Compensator," IECON 2013 - 39th Annual Conference of the IEEE Industrial Electronics Society, Vienna, , pp. 145-150, 2013.

7. Dhanavath Suresh, S.P. Singh, "design of single input fuzzy logic controller for shunt DSTATCOM," IETE journal of research, vol.61, no.5, 2016.

8. H. Akagi, Y. Kanazawa, A. Nabae, "Generalized theory of the instantaneous reactive power in three-phase circuits", Proc. IEEE JIEE IPEC, pp. 821-827, 1983.

9. B. Singh, J. Solanki, "An implementation of an adaptive control algorithm for a three-phase shunt active filter", IEEE Trans. Ind. Electron., vol. 56, no. 8, pp. 2811-2820, Aug. 2009.

10. Malesani, L., Rossetto, L., and Tenti, P.: 'Active filter for reactive power and harmonics compensation'. IEEE Power Electronics Specialist Conf., Vancouver British Columbia, Canada, , pp.321-330, 1986. 